\title{
RETORNO AL DEBATE CONCEPTUAL DE TASA Y TARIFA COMO UN PARÁMETRO DE LOS LÍMITES DEL CONCEPTO DE TRIBUTO. COMENTARIO A LA SENTENCIA DEL TRIBUNAL SUPREMO DE ESPAÑA 5037/2015, DE 23 DE NOVIEMBRE DE 2015, RECAÍDO EN RECURSO DE CASACIÓN $4091 / 2013$.
}

\author{
THE RETURN TO THE DEBATE ABOUT THE CONCEPT OF UTILITY \\ FARES AND THE CONCEPT OF TAXES. \\ COMMENTARY ON THE DECISION OF THE SUPREME COURT OF \\ SPAIN 5037/2015, NOVEMBER 23, 2015, APPEAL IN CASSATION \\ $4091 / 2013$.
}

\section{Patricio Masbernat*}

\begin{abstract}
RESUMEN: El presente artículo comenta una sentencia del Tribunal Supremo de España, en recurso de casación, recaída en un caso en que dos órganos públicos discuten sobre su competencia sobre la determinación de cierta clase de cargas. Dichas cargas, para un órgano estatal (Gobierno Autonómico), constituyen tarifas (prestaciones patrimoniales no tributarias) y, para el otro órgano estatal (ayuntamiento), constituyen tasas (prestaciones patrimoniales tributarias). Esta sentencia pone de relieve la vigencia del debate acerca del ámbito conceptual del tributo, lo que constituye un asunto de gran complejidad y en que convergen diversos elementos, de todo lo cual se hace referencia en este trabajo. El caso dice relación específica con el debate sobre la naturaleza jurídica de la prestación que pagan los usuarios de servicios públicos de abastecimiento domiciliario de agua.
\end{abstract}

Palabras clave: Tributos, tasas, tarifas.

ABSTRACT: This article analyzes a decision of the Supreme Court of Spain, on appeal in cassation, handed down in a case where two public bodies discuss its jurisdiction over the application of certain kinds of charges. Such charges, for a state body (Government of Autonomous Region) constitute utility fares (for provision of public utilities), for the other state body (municipality) are taxes. This judicial decision underscores the validity of the debate about the conceptual scope of the tax, which is a matter of great complexity and converging

\footnotetext{
* Profesor de la Universidad Autónoma de Chile, Instituto de Investigaciones en Derecho. Doctor en Derecho por la Universidad Complutense de Madrid. Dirección Postal: Galvarino Gallardo 1983, Providencia, Santiago. Dirección electrónica: patricio.masbernat@uautonoma.cl. Este artículo forma parte del proyecto CONICyT FONDECyT Regular № 1140290 ("Evaluación crítica y reconstrucción dogmática del concepto y los perfiles del tributo en el sistema jurídico chileno, y sus parámetros justificativos, particularmente fines extrafiscales. Un estudio sustentado en el derecho comparado") del cual el autor es Investigador Responsable; y del proyecto interno de la Vicerrectoría de Investigación y Postgrado de la Universidad Autónoma de Chile, DIUA109-2017.
} 
various elements, all of which referred to in this work. This specific case is related to the payment of house water supply, and about the legal nature of the payment of the users of public utilities.

Key words: Taxes, utility fares, taxation.

\section{INTRODUCCIÓN'}

La sentencia que se comenta en estas líneas trata acerca de un tema fundamental del Derecho tributario, por así decirlo, de la teoría general sobre el concepto de tributo. Lo llamativo es que no se trata de un asunto teórico (el Derecho constituye un asunto de razonamiento práctico), y tanto es así, que un litigio importante (en este caso, de España) se basa en la discusión de dicha categoría y resuelve sobre la base de su análisis.

Como contrapartida, lo llamativo es el escaso desarrollo del tema en la doctrina y jurisprudencia chilenas, y por tanto, su nula recepción normativa, al menos en los términos usuales de países de la OCDE, por ejemplo, de aquellos cuyos sistemas tributarios se acercan cada vez más al nuestro.

Este caso trata acerca de una sentencia del máximo tribunal de justicia español, que conoce de un recurso de casación sobre otra sentencia del máximo órgano judicial de una Comunidad Autónoma, en un contexto de un sistema cuasi federal como es el español. Trata, asimismo, sobre un conflicto de materia tributaria entre un Ayuntamiento (Corporación o ente local) y el gobierno de una Comunidad Autónoma, que se centra en el despliegue legítimo de las competencias de cada uno. Para determinar a quien corresponde fijar el precio del servicio de suministro de agua, necesita dilucidarse la naturaleza jurídica de dicha prestación: si se tratara de tarifas, toca intervenir a la Comunidad Autónoma; si se trata de tasas, es decisión del Ayuntamiento.

En el próximo apartado se entregarán resumidamente algunos elementos técnicos para entender y evaluar la sentencia que se comenta, y en el siguiente se dará noticia de la sentencia, para luego dar cuenta de la conclusión.

Como se observa en este trabajo, el concepto de tributo es un asunto debatido, tanto desde una perspectiva normativa como desde una perspectiva doctrinaria, y tiene enormes consecuencias prácticas, dado que sobre dicha categoría se sustenta todo el sistema tributario, toda la comprensión de lo que vale como la carga tributaria de una persona en una jurisdicción determinada. Solo cabe mencionar, como punto de partida: las categorías tradicionalmente consideradas como tributo (impuesto, tasa, contribución); las otras categorías respecto de las que se discute doctrinariamente su carácter de tributos (precios públicos, cotizaciones previsionales y de salud, etc.); las categorías parafiscales (que constituyen una clase especial y altamente compleja de tributos); las prestaciones patrimoniales de carác-

\footnotetext{
1 Abreviaturas: LRHL, Real Decreto Legislativo 2/2004, de 5 de marzo, por el que se aprueba el texto refundido de la Ley Reguladora de las Haciendas Locales; LRBRL, Ley 7/1985, de 2 de abril, reguladora de las Bases del Régimen Local; FJ, Fundamento Jurídico; CE, Constitución Española; TCE, Tribunal Constitucional Español; STCE, Sentencia del TCE; TSE, Tribunal Supremo de España; STSE, Sentencia del TSE; TSJC, Tribunal Superior de Justicia de Canarias.
} 
ter público; en nuestro medio las categorías introducidas por la jurisprudencia Tribunal Constitucional chileno (v.g., los gravámenes especiales entendidos como prestaciones patrimoniales no tributarias); y todas las clases y tipos de exacciones de riqueza privada bajo fórmulas pretendidas de Derecho privado y no obstante sustentadas en normas de Derecho público, figuras anómalas cada vez más numerosas en nuestro medio y en otras jurisdicciones, que constituyen nada más que representaciones de huida hacia el Derecho privado, justificadas en la necesidad de obtener nuevas fuentes de financiamiento para cada vez más funciones reclamadas para sí por parte de los órganos públicos.

No resulta posible profundizar acerca de todos los elementos implicados en este tema, lo que dejamos a cargo de otra publicación próxima, monográfica específica acerca del concepto de tributo.

\section{ALGUNOS ELEMENTOS PARA EXPLICAR LA SENTENCIA}

Para entender este caso hay que revisar, aunque sea brevemente dada las limitaciones de espacio, algunas categorías: el concepto de tributo; las clases de tributos; las prestaciones pecuniarias de carácter público; las tarifas; las potestades tributaria, impositiva y tarifaria; los servicios públicos, titularidad y gestión, especialmente de suministro de agua potable, etc. Trataremos de ser precisos y deberemos resumir y simplificar solo los elementos necesarios para la comprensión del debate forense a que dio lugar el proceso que finaliza con la sentencia comentada.

En relación con el concepto de tributo, en el Derecho comparado existen diversas definiciones doctrinarias, jurisprudenciales y legales. Pero el problema acerca de lo que el tributo implica no es simple (i.e., de aquellos que se resuelven con definiciones) sino complejo, i.e., de aquellos que se resuelve mediante cadenas argumentativas.

El tributo sobre todo constituye un instituto ${ }^{2}$ o una institución ${ }^{3}$, pues se trata de una categoría compleja y nuclear que identifica determinada clase o tipo de relaciones jurídicas, que compromete estructuras más o menos universales que trascienden las regulaciones locales. Mediante esa institución (el tributo) se logra identificar un conjunto de normas y tipos de casos como propios de una rama del Derecho o pertenecientes a ella. Las normas así identificadas presentan la virtualidad de regular la relación jurídica tributaria ${ }^{4}$.

\footnotetext{
2 García Novoa (2012) p. 58.

3 Un autor lo explica en los siguientes términos: "El vocablo institución ha sido objeto de muchos usos diversos por parte de los juristas, hasta el punto de que algún jurista ilustre prefiere, por ello, no usarlo. Sin embargo, resulta útil didácticamente comenzar advirtiendo que el tributo es una Institución jurídica, si se admite un concepto dado de institución, compartido, por otra parte, por un amplio y autorizado sector doctrinal.

En efecto, si nosotros admitimos que existe una institución jurídica siempre que existe una serie orgánica de normas que regulan relaciones jurídicas, un conjunto de disposiciones de derecho relativas a relaciones jurídicas de una clase determinada (Enneccerus), hemos de admitir también que el tributo es una Institución jurídica”. Pérez de Ayala y Pérez de Ayala (2013) p. 53.

4 La institución jurídica está ligado a los conceptos de norma y relación jurídica, al concepto de ordenamiento jurídico, y reúne relaciones jurídicas con caracteres comunes. JESTAZ (1996) p. 32.
} 
El tributo (como categoría abstracta o normativa) se sustenta en una serie de otras categorías, y principios materiales y formales, y se orientan a finalidades constitucionales, que determinan la especial regulación establecida en el sistema tributario.

En términos más específicos, el tributo constituye una clase de prestación patrimonial de carácter público, como se desprende del art. 31.3 de la CE, de acuerdo a algunos, diferenciada de las multas o sanciones pecuniarias, y según otros, de una tercera clase de prestaciones, como se expondrá más adelante.

En España, la Ley General Tributaria (LGT) define los tributos en su artículo 2.1, como "los ingresos públicos que consisten en prestaciones pecuniarias exigidas por una Administración pública como consecuencia de la realización del supuesto de hecho al que la ley vincula el deber de contribuir, con el fin primordial de obtener los ingresos necesarios para el sostenimiento de los gastos públicos." Agrega su inciso segundo, que "los tributos, además de ser medios para obtener los recursos necesarios para el sostenimiento de los gastos públicos, podrán servir como instrumentos de la política económica general y atender a la realización de los principios y fines contenidos en la Constitución" 5

En segundo término, cabe indicar que usualmente se distinguen, como clases de tributos, las tasas, las contribuciones especiales y los impuestos, que la LGT española define en su art. 2.2, del siguiente modo: "a) Tasas son los tributos cuyo hecho imponible consiste en la utilización privativa o el aprovechamiento especial del dominio público, la prestación de servicios o la realización de actividades en régimen de derecho público que se refieran, afecten o beneficien de modo particular al obligado tributario, cuando los servicios o actividades no sean de solicitud o recepción voluntaria para los obligados tributarios o no se presten o realicen por el sector privado. b) Contribuciones especiales son los tributos cuyo

5 Desde la perspectiva de las normas de mayor jerarquía que se vinculan al caso, son principalmente las siguientes las normas de la CE más directamente vinculadas al tema:

"Artículo 31.

1. Todos contribuirán al sostenimiento de los gastos públicos de acuerdo con su capacidad económica mediante un sistema tributario justo inspirado en los principios de igualdad y progresividad que, en ningún caso, tendrá alcance confiscatorio.

2. El gasto público realizará una asignación equitativa de los recursos públicos, y su programación y ejecución responderán a los criterios de eficiencia y economía.

3. Solo podrán establecerse prestaciones personales o patrimoniales de carácter público con arreglo a la ley.”

"Artículo 131. 1. El Estado, mediante ley, podrá planificar la actividad económica general para atender a las necesidades colectivas, equilibrar y armonizar el desarrollo regional y sectorial y estimular el crecimiento de la renta y de la riqueza y su más justa distribución."

"Artículo 132.

${ }^{1}$ La ley regulará el régimen jurídico de los bienes de dominio público y de los comunales, inspirándose en los principios de inalienabilidad, imprescriptibilidad e inembargabilidad, así como su desafectación.

2. Son bienes de dominio público estatal los que determine la ley y, en todo caso, la zona marítimo-terrestre, las playas, el mar territorial y los recursos naturales de la zona económica y la plataforma continental.

3. Por ley se regularán el Patrimonio del Estado y el Patrimonio Nacional, su administración, defensa y conservación."

"Artículo 133.

1. La potestad originaria para establecer los tributos corresponde exclusivamente al Estado, mediante ley.

2. Las Comunidades Autónomas y las Corporaciones locales podrán establecer y exigir tributos, de acuerdo con

la Constitución y las leyes.

3. Todo beneficio fiscal que afecte a los tributos del Estado deberá establecerse en virtud de ley.” 
hecho imponible consiste en la obtención por el obligado tributario de un beneficio o de un aumento de valor de sus bienes como consecuencia de la realización de obras públicas o del establecimiento o ampliación de servicios públicos. c) Impuestos son los tributos exigidos sin contraprestación cuyo hecho imponible está constituido por negocios, actos o hechos que ponen de manifiesto la capacidad económica del contribuyente." Es posible incluir, desde nuestra perspectiva teórica (aunque sea parcialmente), la categoría de precios públicos, que son definidos por la ley como "contraprestaciones pecuniarias que se satisfagan por la prestación de servicios o la realización de actividades efectuadas en régimen de Derecho público cuando, prestándose también tales servicios o actividades por el sector privado, sean de solicitud voluntaria por parte de los administrados"6.

Con todo, las clases de tributos no solo deben considerarse vinculadas a impuestos, $\operatorname{tasas}^{7}$ y contribuciones, sino también, como se quiera denominar, a otras clases de tributos (o impuestos de toda naturaleza ${ }^{8}$ ) e incluso en ciertos casos a cobros de servicios en régimen de monopolio 9 . Asimismo, debe incorporarse la categoría de parafiscalidad ${ }^{10}$. Esta última constituye una herramienta de política pública destinada a conseguir más recaudación sin verse limitada por las exigencias a que es sometido todo tributo.

Para algunos, posición que compartimos desde nuestra perspectiva teórica, la tasa puede constituir una figura limítrofe con ciertos tipos de exacciones que pudieran no siempre constituir tributos, como los precios públicos ${ }^{11}$ (o las figuras parafiscales) ${ }^{12}$. El precio público constituye un ingreso público, prestación de carácter público percibida por el Estado y demás órganos públicos. Su régimen es de Derecho público, en fondo y procedimiento. Su naturaleza es algo discutible, en cuanto nace ex contractus y ex lege $e^{13}$. A su vez, el precio público se distingue de la cotización previsional y de las exacciones parafiscales, que por regla general la doctrina comparada considera como tipos de tributos.

Ferreiro ha sostenido, en reflexión vinculada a la tasa y al precio público, pero que bien cabe respecto del resto de los tributos, que es de naturaleza política la decisión de que una exacción se considere jurídicamente tributo o no se considere como tal: "Cuando la actividad administrativa sea por su naturaleza inherente al Estado, es decir, cuando (según las concepciones políticas del momento) solo el Estado puede realizarla y sea necesaria para la

\footnotetext{
6 Art. 24 de la Ley 8/1989, de Tasas y Precios Públicos.

7 Las tasas se distinguen de precios públicos, tarifas, cánones, como explica De Mrta (2011) p. 5. Las categorías específicas son discutibles en su clasificación, ya que usualmente caen en la parafiscalidad como explica RIVAS (2006). Sin embargo, estas categorías son defendidas como prestaciones patrimoniales públicas de carácter no tributario, muy usualmente: VILLAR (2000). Sobre su concepto y como herramienta de financiación, ver García-Herrera (2002). Pagés I Galtés (2005).

8 Beltrame (2004) p. 29.

9 Ferreiro (2010) p. 91.

10 Lo explica Rivas (2006). El tributo se diferencia de otras detracciones de riqueza coactiva tales como la expropiación, imposiciones de límites, sanciones, etc., porque tiene por fin satisfacer necesidades públicas. Con todo, puede perseguir fines fiscales o extrafiscales, de acuerdo a TeSAURo (2012) p. 3.

11 Ferreiro ((1991) p. 89 y ss.

12 Estas figuras (tasas, pecios públicos, figuras parafiscales), se sostienen más en un principio conmutativo que en un principio contributivo, conforme a VILLAR (2000) p. 13.

13 Ferreiro (1991) p. 92.
} 
vida de la comunidad su realización por el Estado"14, la exacción será un tributo. Opinión diferente parecen tener otros autores, como Herrera Molina, que se ha manifestado en contra del uso instrumental de estas categorías tributarias ${ }^{15}$.

La doctrina extiende el análisis y la discusión a otras figuras, tales como las exacciones parafiscales ${ }^{16}$ (que constituyen una clase de tributos ${ }^{17}$, anómalos o patológicos) y las prestaciones patrimoniales de carácter público, estas últimas, entendidas en un sentido estricto, i.e., como especie, ya que, como género, las prestaciones patrimoniales de carácter público incluyen a los tributos ${ }^{18}$.

Como los define Martin y Lozano, las exacciones parafiscales se refieren a "detracciones coactivas de carácter económico, caracterizadas porque, pese a tener materialmente los rasgos del tributo, ni se han creado por Ley, ni se gestionan conforme a los procedimientos aplicables a la gestión de los tributos, ni su exacción está prevista en los Presupuestos Generales del Estado", y se refieren a "tributos afectados a unas finalidades concretas y determinadas, caracterizados por la singularidad de su régimen jurídico, tanto en su nacimiento como en su desarrollo y destino final" ${ }^{19}$.

De acuerdo a Ferreiro las exacciones parafiscales "no han seguido o siguen en su establecimiento o aplicación, o en el uso o destino de las sumas que procuran, el régimen normal, típico de los tributos" 20 , pueden haber sido establecidas por norma infralegal (no se crean por ley) $)^{21}$, puede que se gestionen fuera de la órbita de la Administración, que no se integren a presupuestos públicos generales ${ }^{22}$, etc. Constituye un concepto negativo, son

\footnotetext{
14 Ferreiro (1991) pp. 91 y 98. El autor parece algo contradictorio en este punto. Parece ser de la opinión de que el precio público constituye obligación ex contractus, pero la ley es contradictoria en dicho punto.

15 Herrera Molina (2004) expone: "Los fenómenos de transformación entre impuestos y prestaciones patrimoniales sinalagmáticas (especialmente tasas) pueden estar legitimados en razones de practicabilidad administrativa, pero deben examinarse con cautela, pues pueden suponer un ardid para eludir los principios constitucionales a que ha de responder el impuesto o la prestación patrimonial sinalagmática”.

16 SÁnchez (2012) explica que la parafiscalidad surge en España hacia la década de 1940, momento en el cual "por diversas causas - de índole político, administrativo o financiero- aparecen una serie de tasas y exacciones que, sin someterse a normas ni a ninguna regulación genérica fundamental, escapan al principio de legalidad, permitiendo obtener ingresos extrapresupuestarios, afectados a fines específicos o con una gestión no encomendada a órganos de la Administración financiera”.

17 En esto hay consenso, también en Italia (FalsitTa (2012) p. 18). Por su parte, en Francia las exacciones parafiscales, que constituían una suerte de "fiscalidad privada", han quedado incluidas en la noción de "impuestos de toda naturaleza”, desde el año 2004, con la derogación de la ley de 2 de enero de 1959. En Francia, asimismo, se reconocen las figuras particulares de exacciones coactivas y con regímenes propios de los cánones y de las cotizaciones previsionales. El canon exige, de acuerdo lo ha declarado el consejo de Estado, que solo se cobre a los beneficiarios, efectivos, que el servicio solo beneficie a los obligados a pagar la exacción, y que esta se destine íntegramente al servicio prestado (principio de equivalencia) (Beltrame (2004) p. 33).

18 Ley 25/1998, de 13 de julio.

19 Martin y Lozano (1990) p.151.

20 Ferreiro (2010) p. 234.

21 Hay que hacer notar una, aunque sea parcialmente, falta de unidad de la comprensión de este instituto en la doctrina. Ello puede verse al comparar las condiciones expresadas por los autores citados respecto de la parafiscalidad, con las que mencionadas, por ejemplo, por Calvo Ortega (2011) p. 116.

22 En semejantes términos Pérez de Ayala y Pérez de Ayala (2013) p. 65.
} 
parafiscales los tributos no fiscales ${ }^{23}$. Para este autor, se trata de "una anormalidad que puede tener diversos casos y momentos" ${ }^{24}$ y es necesario que sea "reducida al mínimo posible si queremos reducir los perjudiciales efectos que, tanto desde la óptica de los principios constitucionales, como de la política económica conlleva la creación de un sistema fiscal 'paralelo' o 'parafiscal'” 25 . Este autor resalta que, si bien las cotizaciones de seguridad social han sido excluidas de la regulación legal tributaria, es indudable su carácter tributario ${ }^{26}$.

Las razones económicas o políticas de la parafiscalidad se encuentra en "allegar más recursos y para aproximarse a una imposición sobre el beneficio recibido en aquellas actividades o servicios en los que se reconoce un beneficio personal al ciudadano que hace uso del servicio ofrecido por el sector público" ${ }^{27}$. Dicha apreciación es compartida por Rivas ${ }^{28}$, en orden a que la creación de tributos atípicos (parafiscales o prestaciones patrimoniales de carácter público) se debe a que el Estado requiere buscar nuevas formas de financiación de sus gastos (de sus objetivos de políticas públicas definidas como socialmente relevantes) frente a la imposibilidad de seguir aumentando el número y la cuantía de los tributos (y la impopularidad o impracticabilidad política de esta vía).

La parafiscalidad (y cualquier exacción de efecto equivalente al tributo, como las prestaciones patrimoniales de carácter público, en sentido estricto), parafraseando a Varona, constituyen patologías que deben ser corregidas "ya que genera una incontrolada y perturbadora presión fiscal paralela". Agrega dicho autor, que "este fenómeno presenta una gradación, en función al mayor o menor respeto que se conceda a aquellos cauces y según la magnitud de aquellas anomalías, debiendo destacarse que las más perniciosas y que mayor grado de parafiscalidad confieren son la deslegalización y la exclusión de los presupuestos públicos, irregularidades que hoy deben reputarse inconstitucionales"29.

Como se ha expuesto, hay dos formas de comprender las prestaciones patrimoniales de carácter público. Una en sentido amplio y otra en sentido restringido.

Hay autores que consideran que el concepto genérico de "prestación patrimonial de carácter público" solo admite dos categorías concretas, a saber, los tributos y las sanciones o multas $^{30}$ (no reconocen la existencia de otras clases de prestación patrimonial de carácter publico, específicamente no tributarias).

Desde una perspectiva restringida se ha sostenido que las prestaciones pecuniarias de carácter público constituyen una clase específica de exacciones diferentes del tributos y multas, permitidas por la Constitución Española en el art. 31.3, tales como los recargos por prórroga o los tributos de ordenamiento o tributos con fines no fiscales ${ }^{31}$. La autonomía de

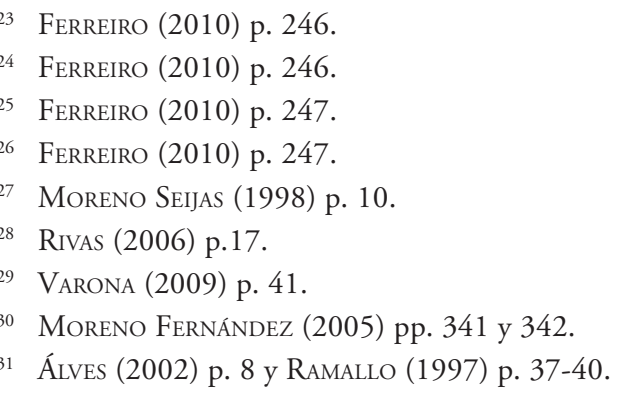


estas cargas ha sido reconocida por el TCE, destacando la decisión Grupo Parlamentario Popular contra Gobierno de España (1995) ${ }^{32}$.

Moreno sostiene que "las diferentes prestaciones patrimoniales, ya tengan fines fiscales o extrafiscales, estimulantes o disuasorias de determinadas conductas, van a tener una naturaleza eminentemente tributaria, y solo cuando se dirijan derechamente a castigar conductas de los ciudadanos, tendrán naturaleza sancionadora" ${ }^{33}$. Este autor describe el fenómeno citando al TCE, el que "para definir la figura de la 'prestación patrimonial de carácter público’ y, en consecuencia, dotarla de un contenido, ha recurrido al análisis de sus características. En este sentido, entiende que "el establecimiento unilateral de la obligación de pago por parte del poder público sin el concurso de la voluntad del sujeto llamado a satisfacerla es, pues, en última instancia, el elemento determinante de la exigencia de reserva de ley", es decir, la coactividad es la nota distintiva fundamental del concepto de prestación patrimonial de carácter público, o lo que es lo mismo, esta clase de prestaciones derivan de una obligación establecida unilateralmente por el poder público "sin el concurso de la voluntad del sujeto llamado a satisfacerla" ${ }^{34}$, eso sí, siempre que al mismo tiempo "la prestación, con independencia de la condición pública o privada de quien la percibe, tenga una inequívoca finalidad de interés público (STCE 182/1997, FJ 15)"35.

Ramallo afirma que "la inexistencia de un concepto constitucional de tributo y su configuración partiendo de las características que le dé el legislador ordinario permiten que este pueda sortear alguno de los requisitos o condiciones que sí se establecen en la propia Constitución". Añade que "mediante esta manipulación por la legislación ordinaria,... pueden aparecer figuras que, implicando para los ciudadanos tener que cumplir prestaciones patrimoniales en favor de entes públicos de distinta naturaleza, sortean el régimen jurídico constitucional que es propio de estas prestaciones cuando se configuran como tributos". Agrega este autor que "este fenómeno ha tenido un excelente banco de pruebas a raíz de la figura de los precios públicos introducida en nuestro ordenamiento jurídico en los años 1988 y 1989", la que ha sido analizada por la STCE 185/1995, la cual busca despejar los siguientes asuntos: "de un lado, los requisitos que debe cumplir una prestación patrimonial para ser considerada, desde la perspectiva constitucional, de carácter público; de otro, en qué consiste el establecimiento con arreglo a la ley, es decir, el grado de presencia que la ley debe tener en este tipo de prestaciones". Sobre el punto, señala el TCE que "una prestación patrimonial tiene carácter público cuando es coactiva", lo que sucede "cuando se da alguna de las dos características siguientes: $1^{\circ}$ ) que no exista libertad 'real y efectiva' en el sujeto que realiza el supuesto de hecho, entendiendo que no existe libertad cuando la actuación del sujeto a la prestación es obligatoria o imprescindible, o dicho en sentido inverso, la actuación será libre (no coactiva) cuando ni sea obligatoria ni sea imprescindible; $2{ }^{\circ}$ ) que la actuación del ente público sea 'de hecho o de derecho' de carácter monopolístico.” Para

32 Grupo Parlamentario Popular contra Gobierno de España (1995). Un análisis de esta sentencia en Martín Fernández (1995). También en Comunidad Autónoma dE CANARIAS CON Ayuntamiento de SANTA CRUZ DE LA PALMa (2015), FJ 50.

33 Moreno Fernández (2005) p.341.

34 Grupo Parlamentario popular contra Gobierno de España (1995), Fu 3.

35 Moreno Fernández (2005) p. 342. 
considerar que existe coactividad en la prestación es suficiente la presencia de uno de los dos requisitos apuntados. En relación al segundo punto se parte de una distinción entre obligaciones bilaterales y unilaterales: "mientras que en las primeras el fundamento del que asume una obligación reside en el consentimiento al cumplimiento de la prestación que constituye el objeto de la relación jurídica, siendo ese consentimiento del sujeto que se obliga lo que permite que sea exigible el cumplimiento de la obligación, en las segundas (en las obligaciones impuestas unilateralmente) ese consentimiento individual no existe debiendo ser sustituido por un consentimiento colectivo, de tal manera que -como señala el TCE- 'la voluntaria aceptación de sus representantes' es la condición de legitimidad constitucional 'cuando un ente público impone coactivamente una prestación patrimonial a los ciudadanos"” (sentencia citada) ${ }^{36}$.

Rivas resume las características de las prestaciones patrimoniales de carácter público en sentido estricto destacando las siguientes notas: prestación coactiva (lo que puede darse en tres supuestos) ${ }^{37}$; puede ser percibida por un ente público o privado; puede ser un ingreso de Derecho público o de Derecho privado; está sometido a reserva de ley; debe respetar el principio de capacidad económica, no necesariamente ha de ser prestación dineraria; tiene que perseguir un interés o finalidad pública; puede constituir una sanción.

Finalmente, respecto de las tarifas, de acuerdo a la tesis mayoritaria, se refieren a otra categoría diferente de los tributos. Es precisamente en las prestaciones patrimoniales de carácter público donde encuentran encaje las tarifas, ciertas tasas, los peajes y los precios administrativos exigidos como contraprestación por determinados servicios públicos o privados de interés general ${ }^{38}$.

Explica Villar que pese a los diferentes esfuerzos doctrinarios ("desde la divisibilidad del servicio publico, hasta la esencialidad para los ciudadanos, pasando por la distinción

\footnotetext{
36 Ramallo (1997) pp. 37-40. Para Ramallo, "Si hemos llegado a la conclusión de que una prestación patrimonial tendrá carácter público, a efectos del art. $31.3 \mathrm{CE}$, cuando se den las circunstancias de no libertad o de monopolio, y de que en este caso es necesaria la 'voluntaria aceptación de los representantes' que deban satisfacerla, un último problema se plantea cuando la prestación es debida por una actuación no realizada directamente por un ente público sino que se realiza a través de alguna de las distintas formas que el ordenamiento tiene previstas para la gestión de los servicios y que ha dado lugar a la llamada 'huida del Derecho público'. Porque la pregunta en estos supuestos será: ¿Cambia de naturaleza la prestación patrimonial satisfecha por el ciudadano por el usuario de un servicio- según sea la forma a través de la cual instrumenten los poderes públicos la gestión de dicho servicio? Porque si el servicio o actividad administrativa cumple aquellos dos requisitos que definen que la prestación que se tiene obligación de pagar constituye una prestación patrimonial pública de carácter coactivo, necesariamente se seguirá la consecuencia de exigirse consentimiento colectivo para el establecimiento de dicha prestación, con independencia de la forma en que el mencionado servicio se gestione.

La forma de gestión de los servicios no es ya condicionante de la naturaleza de la prestación a satisfacer por el ciudadano. La naturaleza de la prestación (pública coactiva asimilada a los tributos, o pública no coactiva) dependerá, por el contrario, de la posición en que se encuentre el obligado al pago frente al acreedor (libertad, monopolio)." Ramallo (1997) pp. 40-41.

37 Los tres casos son los siguientes: (a) Cuando no existe libertad para la realización del supuesto de que genera la obligación de pago de la prestación; (b) cuando la actividad o el servicio requerido sea objetivamente indispensable para satisfacer las necesidades básicas de la vida personal o social de los particulares de acuerdo a las circunstancias sociales de cada momento; (c) cuando existe una actuación monopolística del Estado. RIVAS (2006) pp. 20 y 21.

38 Villar (2000) p. 45.
} 
entre servicios administrativos y servicios públicos económicos, entre otros"), "lo cierto es que es facultad del Legislador decidir el modo y la cuantía en que los ciudadanos deben contribuir a los gastos públicos", siendo dicha decisión "política y de oportunidad"39. La tarifa puede definirse (al hilo de la obra de $\operatorname{Villar}^{40}$ ) como la remuneración o contraprestación exigible al usuario o beneficiario de un servicio público otorgado directa o indirectamente por una Administración, que será de distinta naturaleza según el modo de gestión de dicho servicio.

La existencia de la tarifa deriva de la existencia de un servicio público (calificado legalmente como tal) que se presta, que es objeto de remuneración o contraprestación ${ }^{41}$.

Ahora, los servicios públicos pueden ser gestionados de modo directo o indirecto, es decir, por la misma Administración Pública o mediante una sociedad (aun cuando sea total o parcialmente propiedad de las Administraciones) o a través de un sujeto privado concesionario del servicio ${ }^{42}$.

Se mantiene vigente y actual el debate acerca de la naturaleza jurídica de dicha remuneración o contraprestación, esto es, si la tarifa constituye una tasa o un precio. Esto se resuelve, a juicio de García Novoa, mediante la determinación del gestor, i.e., según si la gestión es a través de las Administraciones y con régimen de Derecho público, o a través de sociedades y en régimen de Derecho privado. En el primer caso se trata de tarifa-tasa y en el otro, de tarifa-precio ${ }^{43}$.

La facultad para fijar tarifas se denomina potestad tarifaria, y es diferente de la potestad tributaria, y la comprensión adecuada de esta última requiere implicación de la categoría de la potestad de imposición.

La potestad tarifaria es la "posibilidad de crear la tarifa o de alterar su cuantía" por parte de la Administración titular del servicio público de que se trata (la cual es otorgada por ley a un órgano público), la cual retiene dicha titularidad no obstante crear el régimen tarifario ${ }^{44}$. De modo más amplio Villar sostiene que es la potestad de crear tarifas, tasas o precios administrativos como contraprestación exigida a los usuarios por la provisión de bienes y servicios a usuarios o consumidores, estableciendo regímenes de gestión directa o indirecta ${ }^{45}$. Su fundamento se encuentra en la titularidad pública de la actividad de que se trata, declarada como servicio público. Si se trata de servicios no esenciales, la Administración puede gestionar los servicios (la prestación a los usuarios) de modo directo (mediante sociedades mercantiles) o indirecto (mediante concesiones) ${ }^{46}$, adoptando la relación prestador-usuario un contenido contractual, bajo la regulación del Derecho privado. Dichos servicios no esenciales, en muchos casos, pueden ser prestados también por particulares.

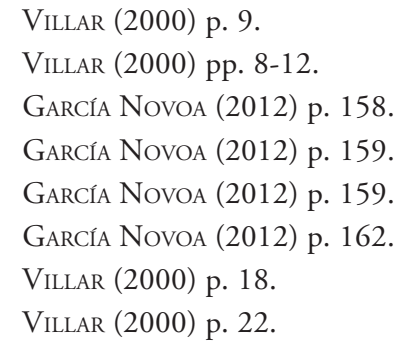


En el caso que se comenta en este trabajo, debemos centrarnos en la idea de titularidad de las corporaciones locales relativa a servicios públicos esenciales. La titularidad de la potestad de reserva de recursos o servicios se atribuye por la Ley 27/2013 a una Administración Pública Territorial, y supone la asunción en exclusiva de dicha titularidad y la exclusión de la iniciativa privada. La ley ha reducido los servicios reservados al abastecimiento domiciliario y depuración de aguas; la recogida, tratamiento y aprovechamiento de residuos; y el transporte público de pasajeros. Ellos se consideran recursos o servicios esenciales ${ }^{47}$.

La potestad tributaria trata de otro asunto. Actualmente, de acuerdo a las tesis más difundidas, y tradicionales, la potestad tributaria es el poder de imponer tributos. Es entendida como expresión de soberanía ${ }^{48}$ y poder $^{49}$ (lo que lleva a llamarla "soberanía tributaria" $\left.{ }^{\prime 0}\right)$, y este poder de sujeción e imperio tiene por objeto la imposición de tributos como obligaciones de pago y la creación de medios de aseguramiento de dicha finalidad ${ }^{51}$. En un confuso constructo teórico, se menciona de un modo no siempre distinguible al Estado legislador (creador del sistema de exacciones patrimoniales obligatorias) y al Estado ejecutor de las exigencias nacidas de las leyes (Administración tributaria) ${ }^{52}$, mediante un conjunto de potestades y derechos y prerrogativas del sujeto activo, que se extienden incluso a diversas prerrogativas de carácter judicial ${ }^{53}$. De ahí la importancia de usar la categoría de potestad de imposición, a la que nos referiremos más adelante.

Pérez de Ayala y Pérez definen la potestad tributaria o poder tributario como la "potestad de crear y establecer los tributos por norma de rango de ley" ${ }^{\text {" }}$. La ley crea el tributo, que se configura como un vínculo jurídico, esto es, como deber de pagar. Dicha potestad es manifestación del poder político, y produce distintas clases de normas tributarias: normas reguladoras de la titularidad y del ejercicio del poder tributario; normas de Teoría General

47 Barrero (2015) Tomo III, p. 89.

48 Las potestades nucleares de la soberanía son las de acuñar monedas, aplicar impuestos, declarar la guerra. Martín Queralt (2001) p. 143.

$49 \mathrm{Al}$ respecto, es ilustrativo el concepto clásico de soberanía que sostienen Aylwin y Azócar, para quienes la "soberanía es la cualidad que tiene el Estado de no hallarse obligado sino por su propia voluntad y de imponer esa voluntad sobre todos los individuos o grupos que son miembros suyos o que se hayan dentro de su territorio”. AYLWIN y AZÓCAR (1996) p. 22.

50 Pérez Royo (2011) p. 81.

51 Pérez de Ayala y Pérez de Ayala (2013) p. 40

52 Como pone de relieve Martín Queralt, "la relativa imprecisión de que está dotada la administración en el ámbito tributario, ha venido propiciada por varios factores": (...) "la no diferenciación entre Estado Legislador o fuente del Derecho, la administración titular de potestades normativas y situaciones jurídicas ante el administrado, contribuyente o no". MARTín QUERALT (2001) p. 141.

53 Esta confusión es puesta de relieve por Martín Queralt (2001) p. 142.

54 La construcción en Estados Unidos es diferente, como se observa en EDREY (2006) p. 118, la que a su vez se desarrolló sobre algunas bases distintas (sobre todo en consideración a una historia más larga) que Inglaterra (Tiley y LoutZenhiser (2012) p. 30), no obstante que hoy todos los sistemas jurídicos tributarios parecen converger por influencia de principios constitucionales comunes progresivamente más profundizados en materia de derechos fundamentales, limitación del poder público, desarrollo de instituciones jurídicas, etc. Y por la influencia del Derecho Internacional, en aspectos tales como la integración política y económica, los tratados de carácter tributario y comercial, los tribunales de derechos humanos, etc. 
del Derecho; normas de Derecho tributario material y formal ${ }^{55}$. La potestad tributaria (poder político) puede distinguirse de la potestad de imposición (potestad administrativa) ${ }^{56}$. No obstante ello, no es posible escindir la potestad tributaria de otras situaciones en que se encuentra la Administración (tales como el derecho de crédito, a la percepción de los tributos $)^{57}$. Si se identifica la potestad tributaria con todos los pasos que conducen a la recolección de recursos financieros ${ }^{58}$, es coherente unir en una sola mano el poder de legislar (establecer el tributo), el poder de determinar la obligación tributaria (“aplicar” la ley), el poder de exigirla (ejecutar el crédito), y luego el poder de destinar dichos fondos a ciertos fines. Esto es uno de nudos problemáticos de la concepción estándar de la potestad tributaria.

Por otro lado, la potestad de imposición "designa al conjunto de potestades administrativas establecidas para la aplicación jurídicamente correcta de los tributos, una vez creados, y puede simplificarse reduciéndola a tres fases o etapas: (a) La de definición y cuantificación de la obligación tributaria concreta de cada contribuyente, de acuerdo con la Ley creadora del impuesto: fase de investigación, comprobación y liquidación de la exacción. Muy a menudo, la ley obliga, inicialmente, al contribuyente a definir y cuantificar su obligación bajo el control ulterior de la Administración; (b) Fase en la que se hace efectiva la obligación tributaria ya definida y cuantificada: fase de recaudación (en los casos en los que la ley obliga al contribuyente a definir y cuantificar su propia deuda y declararla, también le obliga a ingresarla en el momento); (c) Fase que, aun pudiendo superponerse a las anteriores en el tiempo, tiene por finalidad garantizar que las dos citadas anteriormente se desarrollan de acuerdo con lo establecido en la normativa reguladora de las correspondientes figuras fiscales" 59 .

\section{ACERCA DEL DEBATE FORENSE Y LA DECISIÓN JUDICIAL}

Tan debatida es esta cuestión, que el fallo contiene una opinión de mayoría (que constituye la decisión institucional) y una opinión de minoría, entregada por dos magistrados del alto tribunal al que le correspondió decidir.

55 Pérez de Ayala y Pérez de Ayala (2013) p. 41.

56 Por otro lado, la potestad de imposición "designa al conjunto de potestades administrativas establecidas para la aplicación jurídicamente correcta de los tributos, una vez creados, y puede simplificarse reduciéndola a tres fases o etapas: (a) La de definición y cuantificación de la obligación tributaria concreta de cada contribuyente, de acuerdo con la Ley creadora del impuesto: fase de investigación, comprobación y liquidación de la exacción. Muy a menudo, la ley obliga, inicialmente, al contribuyente a definir y cuantificar su obligación bajo el control ulterior de la Administración. (b) Fase en la que se hace efectiva la obligación tributaria ya definida y cuantificada: fase de recaudación. (En los casos en los que la ley obliga al contribuyente a definir y cuantificar su propia deuda y declararla, también le obliga a ingresarla en el momento.) (c) Fase que, aun pudiendo superponerse a las anteriores en el tiempo, tiene por finalidad garantizar que las dos citadas anteriormente se desarrollan de acuerdo con lo establecido en la normativa reguladora de las correspondientes figuras fiscales." Pérez DE AyALA y Pérez de Ayala (2013) p. 42.

57 Como es posible de apreciar en los relatos de los autores, v.g., Martín Queralt (2001) pp. 143 y ss.

58 Giuliani Fonrouge (2011) Tomo I, p. 314, explica que "La expresión poder tributario significa la facultad o la posibilidad de exigir contribuciones con respecto a personas o bienes que se hallan en su jurisdicción".

59 Pérez de Ayala y Pérez de Ayala (2013) p. 42. 
El caso inicia a partir de la modificación por parte del Ayuntamiento de Santa Cruz de la Palma (mediante norma emanada de dicho municipio), de la Ordenanza que fija el monto de la tasa a pagar por los usuarios del servicio municipal de abastecimiento domiciliario de agua potable, cuya gestión ha sido entregada a una sociedad comercial. La Comunidad Autónoma de Canarias, en que se situaba dicho Ayuntamiento, considera que no se trataba de una tasa (asunto de competencia de la Corporación Local) sino de una tarifa, por lo que le cabe participar en su establecimiento o modificación ${ }^{60}$. Habiendo recurrido en procedimiento contencioso administrativo, se desestima su demanda en la instancia del Tribunal Superior de Justicia de la Comunidad Autónoma, y recurre de casación ante el TSE de España. Entonces, el problema esencial del caso radica en determinar la naturaleza jurídica de la remuneración que pagan los usuarios por la provisión de agua en sus domicilios.

Tres fueron los motivos esgrimidos del recurso por la Comunidad Autónoma: (a) La infracción del artículo 2.2 a) de la Ley de la LGT, y de la doctrina expuesta en la propia sentencia recurrida, al discrepar de la conclusión a la que llega de que la contraprestación del servicio tiene el carácter de tasa en este caso y no de tarifa, no obstante reconocer aplicable el nuevo régimen jurídico que se fija con la Ley de Economía Sostenible (el recurrente sustenta su perspectiva en la modificación del art. 2.2 apartado a) de la LGT por parte de la Ley de Economía Sostenible, la que suprime el apartado en relación con lo que debía

${ }^{60}$ En el FJ 10, la sentencia explica que el Tribunal Superior de Justicia de Canarias "rechazó la tesis de la demandante de que la gestión indirecta de un servicio público implicaba la imposición de una tarifa o precio privado sujeta a la legislación sobre política general de precios, que precisaba la autorización de la Comunidad Autónoma...".

La sentencia comentada reproduce el FJ $1^{\circ}$ de la sentencia del Tribunal Superior de Canarias, que explica el nudo fáctico del caso, en los siguientes términos:

"PRIMERO.- La piedra angular del recurso consiste en determinar si en el expediente de Modificación de la Ordenanza Fiscal a que se refiere el recurso, es o no necesaria la intervención de la Comisión Territorial de Precios de la Consejería de Industria y Comercio, ya que mientras el Ayuntamiento demandado sostiene que las Entidades Locales no tienen obligación de solicitar la intervención de la Comunidad Autónoma para la aprobación o modificación de las Tasas por el suministro del agua, en cuanto ello supondría una vulneración de la autonomía tributaria municipal reconocida por el art. 1 de la Ley de Bases de Régimen Local, en relación con los arts. 137 y 140 de la Constitución, disiente, por el contrario, de tal parecer la Comunidad Autónoma recurrente, que se apoya en la tesis basada en que el reconocimiento de la autonomía tributaria local no puede entenderse en el sentido de que los bienes y servicios prestados por los Ayuntamientos queden al margen de la ordenación general de la economía que incumbe al Estado, según el art. 149.1.13 de la Constitución, y de las medidas ejecutivas que asuman las Comunidades Autónomas en virtud de haberse visto afectada la materia de intervención de precios por la transferencia competencial entre el Estado y las Comunidades Autónomas, siendo así que si un suministro prestado por el Ayuntamiento queda afectado por una determinada política de precios, no es nada anormal que sus tarifas, sin perjuicio de su condición de tributos municipales, hayan de someterse al sistema de control establecido, limitación de la autonomía tributaria local con la legislación sobre el control de precios que está claramente reconocida en el art. 107.1 del Texto Refundido de las disposiciones legales vigentes en materia de Régimen Local, aprobado por Real Decreto Legislativo 781/1986, de 18 de abril, que únicamente somete al control de las Comunidades Autónomas o de otra Administración competente la determinación de las tarifas de los servicios cuando así sea necesario con arreglo a la legislación sobre política general de precios". 
de entenderse por actividades o servicios prestados en régimen de derecho público) ${ }^{61}$; (b) Se defiende la declaración de nulidad del acuerdo municipal impugnado por haberse prescindido de la normativa y procedimiento legalmente establecido, al ser necesaria la intervención de la Comisión Territorial de Precios a efectos del régimen de precios autorizados, que es el trámite necesario para la fijación de tarifas; (c) La infracción de la propia doctrina jurisprudencial que recoge el Tribunal de instancia, que atiende a la forma de prestación del servicio a la hora de calificar jurídicamente la retribución del mismo.

La sentencia comentada se hará cargo del primer y tercer punto, considerando innecesario pronunciarse acerca del segundo, desestimando en definitiva el recurso.

En lo sustancial, los argumentos de la decisión del TSE se describen a continuación.

Para el TSE la modificación a la LGT no modifica la interpretación judicial de la norma en análisis, "en lo que respecta a las prestaciones patrimoniales de carácter público, por lo que debemos estar en cuanto a las tasas locales a su regulación, por no haber sido modificada, y que procede de la Ley 25/1998, de 13 de julio, de modificación del régimen legal de tasas estatales y locales y de reordenación de las prestaciones patrimoniales de carácter público, que dio nueva redacción a los artículos 20 y 41, entre otros, de la Ley 39/1988, de 28 de diciembre, de Haciendas Locales, que había introducido en su art. 41 un nuevo concepto de precios públicos de naturaleza no tributaria, en sustitución de las tasas tradicionales", que tuvo por objeto ajustarse a la STCE 185/1995 (FJ 50).

En dicha sentencia, Grupo Parlamentario Popular contra Gobierno de España (1995), el TCE “identifica prestación patrimonial de carácter público con prestación patrimonial coactiva, declarando que constituyen prestaciones patrimoniales de carácter público en el sentido del art. 31.3 de la CE y, por tanto, sometidas a la reserva de ley, los pagos exigibles en dos supuestos concretos: en primer lugar, por la prestación de servicios o la realización de actividades en las que concurra cualquiera de las circunstancias siguientes: que sean de solicitud o recepción obligatoria; que sean realizadas por el poder público en monopolio de hecho o de derecho; o que sean 'objetivamente indispensables para poder satisfacer las necesidades básicas de la vida personal o social de los particulares de acuerdo con las circunstancias sociales de cada momento y lugar' y, en segundo lugar, por la utilización privativa o el aprovechamiento especial del dominio púbico" (FJ 5º).

Por el contrario, el TSE expresa que "no exige que el servicio deba prestarse en régimen de derecho público", lo cual fue en la posterior STCE 233/1999, sobre la Ley Reguladora de las Haciendas Locales, cuando al definir las prestaciones patrimoniales de carácter público vuelve a prescindir del régimen jurídico con que se presta el servicio, precisando

61 Versión anterior a la Ley 2/2011, art. 2.2 LGT:

“a) Tasas son los tributos cuyo hecho imponible consiste en la utilización privativa o el aprovechamiento especial del dominio público, la prestación de servicios o la realización de actividades en régimen de derecho público que se refieran, afecten o beneficien de modo particular al obligado tributario, cuando los servicios o actividades no sean de solicitud o recepción voluntaria para los obligados tributarios o no se presten o realicen por el sector privado.

Se entenderá que los servicios se prestan o las actividades se realizan en régimen de derecho público cuando se lleven a cabo mediante cualquiera de las formas previstas en la legislación administrativa para la gestión del servicio público y su titularidad corresponda a un ente público".

b) En la versión posterior a la vigencia de la Ley 2/2011, se elimina el inciso segundo del art. 2.2 LGT. 
además que 'los precios públicos que hemos identificado como prestaciones de carácter público son materialmente tributos'” (FJ 50).

En el FJ $6^{\circ}$, la sentencia en comento cita la LRHL que, sujetándose a la doctrina del TCE, regula el hecho imponible de la tasa en términos que los ayuntamientos pueden establecer tasas por utilización privativa o utilización del dominio público y prestación de servicios o realización de actividades administrativas de competencia local que se refieran, afecten, o beneficien de modo particular, a los sujetos pasivos. Cabe la exigencia de tasas en esos casos, cuando se presenten las circunstancias siguientes: "(a) Que no sean de solicitud o recepción voluntaria para los administrados. A estos efectos no se considerará voluntaria la solicitud o la recepción por parte de los administrados: cuando venga impuesta por disposiciones legales o reglamentarias; cuando los bienes, servicios o actividades requeridas sean imprescindibles para la vida privada o social del solicitante. (b) Que no se presten o realicen por el sector privado, esté o no establecida su reserva a favor del sector público conforme a la normativa vigente".

Finalmente, la sentencia recuerda que la LRHL describe los servicios o actividades por las que las entidades locales pueden establecer tasas, entre ellas, "la distribución de agua, gas y electricidad y otros abastecimientos públicos, incluidos los derechos de enganche de líneas y colocación y utilización de contadores e instalaciones análogas, cuando tales servicios o suministros sean prestados por entidades locales".

En el caso concreto, esta sentencia cita a la que es objeto del recurso de casación, proveniente del Tribunal Superior de Canarias, en cuanto esta última describe la forma en que se gestiona el suministro de agua en concreto, de forma muy extensa, en su FJ $5^{\circ}$ : “...ejerciendo asimismo el Ayuntamiento cualquier otra actuación en materias que impliquen ejercicio de autoridad, todo lo cual se explicita en la cláusula IV.II a) del pliego de condiciones administrativas particulares que rigen la concesión, lógica derivación es que la contraprestación al servicio de abastecimiento de agua que nos ocupa no puede tener otra calificación que la de tasa, en cuanto se configuran en aquél una relación de naturaleza tributaria, entre los usuarios del servicio y la Administración, y otra, de carácter contractual, entre el prestador del servicio (la concesionaria Canaragua S.A.) y la Administración, lo que determina que sea el Ayuntamiento de Santa Cruz de la Palma quien gestione directamente de los consumidores el cobro del servicio y retribuya luego al concesionario con el importe recaudado con singularidad incluso, a efectos de garantizar la separación de los ingresos derivados del cobro de 'tasas' y no tarifas objeto de dicha concesión del resto de los ingresos de derecho público, de depositar en cuentas restringidas de recaudación los referidos ingresos para su posterior entrega al concesionario"62.

62 Al hilo de dicho análisis, el Tribunal Superior de Canarias en su sentencia FJ 3º, describe la diferencia entre tasas y tarifas, desde la doctrina o teoría, aplicable al caso de acuerdo a sus circunstancias concretas: “...en el sistema de la tasa surgen dos tipos de relaciones jurídicas, una tributaria, entre el usuario del servicio y la Administración, y otra de carácter contractual, entre el prestador del servicio y la Administración, siendo, pues, los elementos disfuncionales de la tasa que el gestor deja de cobrar directamente del usuario y su remuneración pasa a depender del pago que lleve a cabo la Administración a partir de los ingresos que existan en su presupuesto (certus incertus quando), con las resultas de que habrá de cobrar del presupuesto público mediante la correspondiente factura, sujeta al pago de IVA o IGIC y de acuerdo con lo dispuesto en el Real Decreto 1496/2003, y que la Administración deberá abonar conforme a las reglas que, para el pago del precio, establece 
En su FJ 7o, el TSE declara que, siguiendo la doctrina constitucional, ha sido del criterio de que "la forma gestora [del servicio público] es irrelevante [que el servicio público de suministro de agua potable sea prestado mediante concesión administrativa] para delimitar el ámbito de aplicación de las tasas ["la forma de gestión del servicio no afecta a la naturaleza de la prestación, siempre que su titularidad siga siendo pública, como sucede en los supuestos de concesión"]; y que lo esencial era determinar si estamos ante prestaciones coactivas por servicios de carácter obligatorio, indispensables o monopolísticos", lo que se mantiene no obstante la modificación de la LGT aludida, "máxime cuando los conceptos de prestaciones patrimoniales de carácter público y de tributos son recordados también por el Tribunal Constitucional en la sentencia 102/2005, de 20 de abril, que estima la cuestión de inconstitucionalidad y declara inconstitucionales y nulos los apartados 1 y 2 del art. 70 de la Ley 27/1992, de 24 de noviembre, de Puertos del Estado y de la Marina Mercante, en la medida en que califica como 'precios privados' contraprestaciones por servicios portuarios que constituyen prestaciones patrimoniales de carácter público, siendo tributos, con independencia de que los denominados servicios portuarios sean prestados por la Autoridad portuaria de forma directa o indirecta" ${ }^{3}$.

Por otro lado, el voto disidente, particular o de minoría de la sentencia comentada, emitido por dos magistrados del alto tribunal, fue de la opinión de estimar el recurso presentado, por los fundamentos que se exponen a continuación.

Sostiene este voto que la mayoría no interpreta adecuadamente la modificación de la LGT. Aboga por respetar los ámbitos entre potestad tributaria y potestad tarifaria, que históricamente han sido parte del ordenamiento. No obstante los requisitos legales generales de tasas y tarifas, se reconoce a la Administración titular del servicio una cierta facultad discrecional que permitía regular la contraprestación como tasa o tarifa ${ }^{64}$.

la legislación de contratos públicos, con la singularidad, además, de que en el ámbito de una relación tributaria, el impago de la tasa solo podrá exigirse mediante el preceptivo procedimiento de apremio y sin poder proceder a la no prestación del servicio o suspensión del suministro, al tener el gestor que continuar prestando el servicio sin que exista el pago del mismo, disfuncionalidades todas ellas que, por el contrario, no se dibujan en la figura de la tarifa, donde al haber una relación privada entre usuario y concesionario, la cuantía de la tarifa permite identificar los dos elementos propios del precio de un servicio prestado por un particular, su coste y el legítimo beneficio industrial, y posibilita, a la vez, la adaptación a la evolución del coste del servicio, con mantenimiento del equilibrio económico inicial y la buena marcha de la prestación ante las alteraciones del coste por circunstancias imprevisibles, sin olvidar tampoco que el gestor, en una relación privada, puede dejar de prestar el servicio de acuerdo con lo establecido en el reglamento del servicio y a través del respeto a las garantías procedimentales establecidas".

63 Para los lectores más entendidos, cabe agregar última frase de este FJ, que sostiene que "Esta posición implica matizar lo que declaramos en la reciente sentencia de 28 de septiembre de 2015 (casación 2042/2013), cuyo alcance ha de entenderse en relación con el supuesto de servicio funerario allí examinado, prestado por empresa de capital mixto, participada por mancomunidad municipal, en tanto que fue liberalizado por el Real Decreto Ley 7/1996 y, por tanto, de la prestación de servicios en régimen de derecho privado".

64 El FJ 7o indica que la opción discrecional entre la configuración de la contraprestación como tasa o como precio y la opción por una modalidad de gestión directa o indirecta está limitada y legalmente predeterminada cuando el objeto de la actividad o servicio implica ejercicio de autoridad, supuesto en los que se impone la gestión directa por la propia Administración o mediante un organismo autónomo, como se deduce el artículo 85.3 de la LRBRL ("en ningún caso podrán prestarse por gestión indirecta ni mediante sociedad mercantil de capital social exclusivamente local los servicios que impliquen ejercicio de autoridad”) en cuyo caso las contrapresta- 
Destaca en su fundamento $3^{\circ}$ que el TSE “en una larga línea jurisprudencial, distinguió la naturaleza de la contraprestación según que la tarifa correspondiese a prestación del servicio por un concesionario en régimen de gestión indirecta o el servicio se prestase directamente por la Administración titular. En el primer caso se estaba ante un precio privado; se trataba de contraprestaciones percibidas directamente por los concesionarios de servicios públicos como remuneración del servicio, aunque la potestad tarifaria correspondiera a la Administración concedente. En el segundo caso, al prestar la Administración el servicio en régimen de gestión directa se entendía que la naturaleza jurídica de la percepción era la de una tasa”.

Como consecuencia de la modificación de la LGT del año 2011, "parece posible recuperar las ideas de precio y beneficio para los servicios públicos gestionados por concesionarios, e incorporar a los servicios públicos en régimen de concesión o de gestión indirecta los criterios de la autofinanciación y del equilibrio económico del contrato" 65 .

Ahora, de acuerdo LRHL, "solo son tasas o precios públicos las contraprestaciones para la realización de actividades o prestaciones de servicios en régimen de derecho público", donde "la expresión 'en régimen de derecho público' parece que puede referirse a las formas de gestión en que la Administración actúa mediante su personalidad jurídico-pública ordinaria o bien adopta personalidades diferenciadas pero siempre de naturaleza pública, y con la finalidad de ejercer una actividad pública o prestar un servicio público. Por tanto, según esta interpretación, habrían de quedar excluidas la realización de actividades y la prestación de servicios en régimen de derecho privado, incluyendo tanto las forma de gestión mediante personalidad diferenciada con naturaleza jurídico privada como la gestión contratada a particulares".

Finalmente, plantea que "sostener que la forma de gestión de derecho privado no altera la naturaleza pública de la exacción equivaldría a eliminar las tarifas como medio de remuneración del gestor privado, y a establecer el régimen de subvención como único y obligatorio medio de retribución. Y resulta que la tarifa y la subvención son fórmulas de retribución de los gestores del servicio que, separada o conjuntamente, son de elección discrecional por parte de la Administración titular del servicio." (Fundamento 50) ${ }^{66}$.

ciones de los servicios públicos prestados directamente han de tener, necesariamente, la naturaleza de tasa o de precios públicos, en los términos que impone la Ley de Tasas y Precios Públicos y la LRHL. Pero en cualquiera de las otras formas de gestión directa o indirecta, de acuerdo a la Ley Reguladora de la Bases de Régimen Local, mediante alguna de las modalidades de contrato administrativo de gestión de servicios públicos del Texto Refundido de la Ley de Contratos del Sector Público, la Administración titular del servicio puede optar por retribuir al gestor mediante una tarifa o precio a satisfacer directamente por los usuarios, una retribución de la propia Administración, o una combinación de ambas formas de retribución económica.

65 Fundamento $4^{\circ}$ de la sentencia comentada.

66 El FJ $6^{\circ}$ es expresivo de la distinción entre tarifas y precios privados (precios de mercado), ya que las tarifas se encuentran reguladas mediante procedimientos de fijación y de modificación preestablecidos por la Administración y que resuelve ella misma, "en el caso de las sociedades mercantiles públicas es el procedimiento establecido en el reglamento del servicio o en el régimen económico financiero establecido entre la Administración titular del servicio y su empresa pública; y en el caso del concesionario y otros contratistas gestores indirectos de servicios en el régimen que resulte del pliego de condiciones". 


\section{CONCLUSIONES}

Es posible destacar algunos aspectos a partir de lo hasta aquí analizado.

En primer término, el debate abierto acerca del concepto de tributo, y particularmente, acerca de las diferentes figuras que se identifican con dicha categoría.

En segundo término, los diferentes enfoques interpretativos posibles de la ley tributaria, derivado de la complejidad del sistema jurídico tributario: no hay una única respuesta correcta, hay una plausible compitiendo con otras que también parecen plausibles. Ahora, nosotros compartimos la opinión de la sentencia.

Por otro lado, las innumerables categorías, cada una de enorme complejidad, que se encuentran involucradas en una discusión que para muchos parece fácil, pero que realmente no lo es. Pareciera, a partir de este caso, que la distinción entre casos fáciles y casos difíciles no es ni clara ni plenamente operativa en la práctica, frente a los casos concretos.

Respecto del propio caso comentado, por cierto que parecen existir ciertas contradicciones entre sentencias del TSE, y no siempre una única forma de entender la doctrina del Tribunal Constitucional, y sin ir más lejos, la STSE recaída en Funerarias Leonesas S.A. contra Mancomunidad Municipal de Servicios Funerarios y de Cementerios SERFUNLE (2015).

Las figuras de tasas, precios públicos, tarifas, prestaciones patrimoniales de carácter pública, figuras parafiscales, etc. son de difícil delimitación, no solo desde la perspectiva doctrinaria, sino también desde la perspectiva normativa, por lo que para lograr la mejor solución posible en los litigios siempre se requerirá de una interpretación justificada, de una fundamentación suficiente, considerando todos los elementos jurídicos (teóricos y normativos) y todos los elementos facticos, del caso concreto.

Finalmente, cabe destacar que la doctrina tampoco ha sido unánime en juzgar esta sentencia, lo que muestra que las cuestiones de que trata continúan abiertas al debate.

\section{BIBLIOGRAFÍA CITADA}

Alves Portella, Andre (2002): "Prestaciones patrimoniales de carácter público. Las prestaciones pecuniarias coactivas no-tributarias", Dereito Revista Xurídica da Universidade de Santiago de Compostela, Vol. 11, No 1: pp. 7-24.

Aylwin, Patricio y Azócar, Eduardo (1996): Derecho administrativo (Santiago de Chile, Editorial Universidad Nacional Andrés Bello).

Barrero, Concepción (2015): Lecciones de Derecho administrativo, Tomo III (Pamplona, Editorial Aranzadi).

Beltrame, Pierre (2004): Introducción a la fiscalidad en Francia (Barcelona, Editorial Atelier).

Calvo Ortega, Rafael (2011): Curso de Derecho financiero (Pamplona, Editorial Thomson Reuters Civitas).

De Mita, Enrico (2011): Principi di diritto tributario (Milan, Editorial Giuffre).

Edrey, Yoseph (2007): "Constitutional review and Tax Law: an analytical framework". American University Law Review, Vol. 56, No 5: pp. 1187-1228. 
FalsitTA, Gaspare (2012): Manuale di Diritto tributario (Padova, Editorial CEDAM).

Ferreiro Lapatza, José Juan (2010): Instituciones de Derecho tributario (Madrid, Editorial Marcial Pons).

Ferreiro Lapatza, José Juan (1991): “Tasas y precios. Los precios públicos”, Revista del Instituto Peruano de Derecho Tributario, No 21: pp. 89-102.

García-Herrera Blanco, Cristina (2002): "La gestión privada de los servicios públicos y las tasas a debate", Boletín Aranzadi Fiscal No12/2002, Parte Artículo. Aranzadi, Pamplona. Disponible en Base de datos: http://www.westlaw.es/. Identificador BIB $2002 \backslash 2017$.

García Novoa, César (2012): El concepto de tributo (Buenos Aires, Editorial Marcial Pons).

Giuliani Fonrouge, Carlos (2011): Derecho Financiero, Tomo I (Buenos Aires, Editorial La Ley, décima edición).

Herrera Molina, Pedro M. (2004): "La irrelevancia jurídica del 'concepto constitucional de tributo”. Revista Quincena Fiscal No 2/2004, Parte Artículo. Aranzadi, Pamplona. Disponible en Base de datos: http://www.westlaw.es/. Identificador BIB 2004167

Jestaz, Phillipe (1996): El derecho (trad. Ramón Domínguez, Santiago, Editorial Jurídica de Chile).

Moreno Fernández, Juan Ignacio (2005): “Tasas y precios públicos: algunas consideraciones a la luz de la doctrina constitucional", Serie Claves del Gobierno Local, 4 Fundación Democracia y Gobierno Local: pp. 339-381.

Moreno Seijas, José María (1998): La tasa y el precio público como instrumentos de financiación, P.T. No 7/98 (Madrid, IEF).

Martin Queralt, Juan (2001): "La potestad tributaria”, en AMATUCCI, Andrea (director), Tratado de Derecho Tributario, Tomo I (Bogotá, Editorial Temis).

Martín Fernández, Francisco Javier (1995): "Los precios públicos y la Sentencia del Tribunal Constitucional 185/1995, de 14 diciembre", Jurisprudencia Tributaria Aranzadi Tomo III, Parte Estudio. Aranzadi, Pamplona. Disponible en Base de datos: http:// www.westlaw.es/. Identificador BIB 1995\111.

Martín Queralt, Juan y Lozano Serrano, Carmelo (1990): Curso de Derecho Financiero y Tributario (Madrid, Editorial Tecnos).

Pagés I Galtés, Joan (2005): "El concepto de tarifa en la LGT de 2003: Aspectos dogmáticos y positivos", Revista española de Derecho Financiero No126/2005, Parte Estudios. Civitas, Pamplona. Disponible en Base de datos: http://www.westlaw.es/. Identificador BIB 2005\1197

Pérez de Ayala, José Luis y Miguel Pérez de Ayala Berrecil (2013): Fundamentos de Derecho Tributario (Madrid, Editorial Dykinson).

Pérez Royo, Fernando (2011): Derecho Financiero y Tributario. Parte General (Pamplona, Editorial Thomson Reuters Civitas).

Ramallo, Juan (1997): "Hacia un concepto constitucional de tributo", en PalaO, Carlos y Ramallo, Juan, Temas pendientes de Derecho Tributario (Barcelona CEDECS), pp. 3146.

RIVAS, Estela (2006): Los tributos atípicos (Madrid, Marcial Pons). 
Sánchez Galiana, José Antonio (2012): "Configuración y régimen jurídico de las tasas en el Ordenamiento tributario español. Fiscalidad, parafiscalidad y extrafiscalidad”, Revista Española de Derecho Financiero No153/2012, Parte Estudios. Civitas, Pamplona. Disponible en Base de datos: http://www.westlaw.es/. Identificador BIB $2012 \backslash 449$

Tesauro, Francesco (2012): Compendio di Diritto Tributario (Milán, Editorial UTET, cuarta edición).

Tiley, John y Loutzenhiser, Gleen (2012): Revenue Law (Hart Publishing, Oxford, Oxford University Press).

Varona Alabern, Juan Enrique (2009): Extrafiscalidad y dogmática tributaria (Madrid, Editorial Marcial Pons).

VILlar Rojas, Francisco José (2000): Tarifas, tasas, peajes y precios administrativos (Granada, Editorial Comares).

\section{NORMAS CITADAS}

Ley 8/1989, de 13 de abril, de Tasas y Precios Públicos.

LEY 25/1998, de 13 de julio, de modificación del Régimen Legal de las Tasas Estatales y Locales y de Reordenación de las Prestaciones Patrimoniales de Carácter Público.

Ley 58/2003, de 17 de diciembre, General Tributaria.

Real Decreto Legislativo 2/2004, de 5 de marzo, por el que se aprueba el texto refundido de la Ley Reguladora de las Haciendas Locales.

Ley 2/2011, de 4 de marzo, de Economía Sostenible.

LEY 27/2013, de 27 de diciembre, de racionalización y sostenibilidad de la Administración Local.

\section{JURISPRUDENCIA CITADA}

Grupo Parlamentario Popular contra Gobierno de España (1995): Tribunal Constitucional Español 185/1995, 12 de enero, recurso de inconstitucionalidad contra la Ley 13/1989, de 13 de abril, de Tasas y Precios Públicos. Sentencia del, Disponible en: http://hj.tribunalconstitucional.es/docs/BOE/BOE-T-1996-748.pdf [fecha de consulta: 2 de marzo de 2016].

Funerarias Leonesas S.A. Contra Mancomunidad Municipal de SeRVICios Funerarios y de CEMENTERIOS SERFUNLE (2015): Tribunal Supremo de España, de 28 de septiembre de 2015, en casación 2042/2013 (ROJ: STS 3990/2015 - ECLI:ES:TS:2015:3990) Disponible en: http://www.poderjudicial.es/movil/GetDocument.do?from=public\&referen $\mathrm{ce}=7487530$.

[fecha de consulta: 2 de marzo de 2016]

Comunidad Autónoma de Canarias con Ayuntamiento de Santa CRuz de la Palma (2015): Tribunal Supremo de España, de 23 de noviembre de 2015, en Recurso 4091/2013 (ROJ: STS 5037/2015 - ECLI:ES:TS:2015:5037). Disponible en: http://www.poderjudicial.es/movil/GetDocument.do?from=public\&reference $=7551594$

[fecha de consulta: 2 de marzo de 2016] 